\title{
Comparative study of infant and child mortality: The case of Kenya and South Africa
}

\author{
Moses K. Kibet \\ Population Training and Research Unit, North West University \\ Moses.Kibet@nwu.ac.za
}

\section{Abstract}

Comparisons of infant and child mortality between populations, both within and between countries, are important because they highlight causative factors of mortality, which can be addressed by health policies and programmes seeking to reduce high mortality at the young ages. Such information is useful for demographic assessment of the population and the evaluation of health policies and programmes. This study undertakes a comparative analysis of neonatal, post-neonatal and child mortality using the 1998 South African Demographic and Health Survey and the 2003 Kenya Demographic and Health Survey. Two methods of analysis are used in this study. First variations in infant and child mortality levels by population groups are investigated through bivariate analysis which forms the basis for the logistic analysis. The results from the bivariate analysis show the existence of linkages between mother's and partner's levels of education, literacy, urban/rural place of residence, ethnicity, birth order, age of mother at the time of birth of child, age of mother at first marriage, mother's occupation, water supply and health facilities and their children's survival chances. Logistic analysis revealed that ethnicity, type of toilet facilities, literacy and birth order explain most of the variations in infant and child mortality in Kenya while mother's educational attainment and type of toilet facilities were the main variables of importance for South Africa. These findings have important implications on efforts to reduce gaps in mortality differentials. For example the existing socio-economic and demographic differentials in infant and child mortality in the two countries can be reduced through provision of equitable high quality education, proper sanitation, discouragement of early marriage and early childbearing among others.

\section{Résumé}

Les comparaisons de bébé et la mortalité enfant entre les populations, dans et entre les pays sont important parce qu'ils soulignent des facteurs causaux de mortalité, qui peut être adressée par les politiques de santé et les programmes cherchant à réduire l'haute mortalité aux jeunes âges. Telles informations sont utiles pour l'évaluation démographique de la population et l'évaluation de politiques de santé et les programmes. Cette étude entreprend une analyse comparative de mortalité néo-natale, poste-néo-natal et enfant utilisant le 1998 du sud africain Démographique et Enquête de Santé et le 2003 Kenya Démographique et Enquête de Santé. Deux méthodes d'analyse sont utilisées dans cette étude. Les premières variations dans le bébé et les niveaux de mortalité enfant par les groupes de population sont examinées par l'analyse de bivariate qui forme la base pour l'analyse logistique. 
Les résultats de l'analyse de bivariate montrent l'existence de liens entre les niveaux de la mère et partenaire d'éducation, l'alphabétisation, le lieu urbain/ rural de résidence, l'ethnicité, l'ordre de naissance, l'âge de mère lors de naissance d'enfant, l'âge de mère au premier mariage, l'occupation de la mère, la provision d'eau et les facilités de santé et leurs hasards de survie des enfants. L'analyse logistique a révélé cette ethnicité, ce type de facilités de toilette, l'ordre d'alphabétisation et naissance explique la plupart des variations dans le bébé et la mortalité enfant au Kenya pendant que réalisation de la mère éducatifs et le type de facilités de toilette étaient les variables principales d'importance pour Afrique du Sud. Ces conclusions ont des implications importantes sur les efforts pour réduire des écarts dans les écarts de mortalité. Par exemple l'exister les écarts socio-économique et démographique dans le bébé et la mortalité enfant dans les deux pays peuvent être réduits par la provision d'éducation de qualité supérieure équitable, le système sanitaire correct, le découragement de tôt mariage et tôt la maternité parmi d'autres.

\section{Introduction}

The purpose of this paper is to undertake a comparative analysis of neonatal, post-neonatal and child mortality between Kenya and South Africa. Childhood mortality data from the 1998 South African Demographic and Health Survey (SADHS) and the 2003 Kenya Demographic and Health Survey (KDHS) are examined.

Comparative studies of infant and child mortality are very important because they highlight causative factors of mortality, which can be addressed by health policies and programmes seeking to reduce high mortality at the young ages. Such information is useful for demographic assessment of the population and the evaluation of health policies and programmes. In particular infant mortality rate reflects economic and social conditions for the health of mothers and newborns, the well-being of a society as well as the effectiveness of health systems. It also indicates health disparities between populations, both within and between countries. Information on mortality of children also serves the needs of organizations which provide health services by identifying the population groups whose children experience high mortality risks. According to the 2005 United Nations Human Development Report no indicator captures the divergence in human development opportunity more powerfully than child mortality (UNDP, 2005). It is therefore expected that the results of this study will be of immense use not only to policy-makers but also to academicians and others whose research interests may be linked to studies of infant and child mortality in Kenya and South Africa or any other developing country of the world.

Whereas infant and child mortality has been studied widely in both countries there still exist unanswered questions. For example are there any variations in the factors that contribute to reduction in infant and child mortality differentials between the two countries? There is still an unmet need to determine the factors that underplay or explicate channels through which socioeconomic and demographic factors influence child mortality differentials, so that programmes seeking to reduce lev- 
els further, can focus their efforts purposefully. The researcher believes that the findings of this study will contribute towards filling this important gap.

This study could not utilize the 2003 South Africa Demographic and Health Survey due to the unreliability of the information on infant and child mortality collected in that survey. According to the Demographic and Health Survey Report (Department of Health, Medical Research Council, OrcMacro. 2007: p.II4), the child mortality estimates from the 2003 South Africa Demographic and Health Survey estimates do not reflect reality because they are lower than would be expected in the context of the AIDS epidemic in South Africa. Whereas the 1998 South Africa Demographic and Health Survey 5 year retrospective estimates of infant, child and under-five mortality rates are consistent with the estimates obtained from the 1988-1992 Human Science Research Council (HSRC) Survey, there exist inconsistencies with the findings of the 2003 Demographic and Health Survey. Given these data quality concerns, the author found it extremely difficult to undertake a meaningful analysis of infant and child mortality levels and differentials between sub-groups using the 2003 South African Demographic Survey.

The 2008-09 Kenya Demographic and Health Survey is still ongoing hence the study could not capture current realities such as the 2007 post election violence and internal displacement of persons in Kenya which are likely to have mortality implications especially for mothers and children. Nevertheless the study and recommendations are considered relevant for Kenya.
In the following sections of the paper a literature review, theoretical framework, description of sources and types of data, methods of analysis and discussion of the results obtained through bivariate and logistic analysis are presented.

\section{Review of literature and theoretical framework}

Kenya and South Africa are among the countries of the sub-Saharan African region that have experienced increases in mortality over the recent few years. The most recent estimates of mortality, for example, indicate remarkable improvements in the level of mortality until the early 1990's when mortality began to take an upward trend. For example in Kenya, infant mortality rate decreased from 119 deaths per 1000 live births in 1969 to 88 in 1979 and further to 66 deaths per 1000 live births in 1989 and then it experienced an upsurge to 69 in 2004. Expectation of life at birth increased from 50 years in 1969 to 60 in 1989. According to the UNFPA (2004) State of the World Population Report, Kenya's life expectancy had dropped to an alarming average of 45 years with life expectancy for men in Kenya at 44 years compared to 46 years for women.

Rutaremwa (2002) in a comparative study of the differentials in under-five mortality in Uganda, Kenya and Tanzania found less under-five mortality risks for Kenya than Uganda and Tanzania. Though several correlates of under-five mortality are examined in that study, mother's educational level attainment and household type of toilet facility are the most important.

Similarly the historical trend of 
South African mortality situation, suggests rising mortality in recent years due to mortality impact of AIDS which is a serious problem in South Africa. Mortality rates based on the 1996 South African census indicate that female life expectancy at birth rose from 57.6 years in 1970 to 64.5 years in 1996. According to Udjo (2004) life expectancy at birth in the African population in $200 \mathrm{l}$ was estimated at 56 years which is lower than the estimated level in 1970s. The UN $(1999,2000)$ overall estimates for South Africa show declines in infant mortality rate from 67 per thousand in 1982 to 58 in 1997. Adjusted results from the SADHS suggest that between 1992 and 1997 under-five mortality rose from 53 to 71 per 1000 and infant mortality from 39 to 56 per 1000. This rise in child mortality, according to Nannan et al. (2000), can be attributed to pediatric AIDS. The prevalence of HIV amongst antenatal clinic attendees increased at a rate of $0.7 \%$ in 1990 to $26.5 \%$ in 2002 (Department of Health, 2003).

Mencarini (1999) in a study of infant mortality in South Africa confirms a picture of great demographic differences between racial South African groups, not only in terms of child mortality levels, but also in their determinants. According to the study race is the most important factor in economic, social and demographic differences, remaining statistically significant in the multiple regression analysis of child mortality, also after controlling for several factors, such as level of poverty, education and employment. The socio-economic and demographic variation is greater between whites and blacks than for Coloureds and Asians. This is also sup- ported by a study by Romani and Anderson (2002).

Studies have shown that neonatal mortality is more likely to be affected by endogenous factors while infant mortality is more likely to be affected by exogenous factors. Endogenous infant mortality is approximately equivalent to neonatal death (Wrigley, 1977). Therefore in order to have a clear understanding of infant and child mortality, it is important to have a clear distinction between deaths which occur at different ages. This paper presents mortality rates in terms of the proportions of children dying before reaching a certain age. For example, neonatal mortality and post-neonatal rates are calculated as the proportions of children dying during the first month and the subsequent eleven months of life, respectively. These two components of mortality constitute infant mortality rate which is the probability of dying before the first birthday. Child mortality refers to the proportion of children dying between the first and fifth birthdays.

The determinants of each of these components of under-five mortality are distinct. Neonatal mortality in particular is conditioned by the circumstances of childbirth, environmental circumstances of the mother prior to birth and the influence of breastfeeding while post-neonatal and child mortality is mostly conditioned by environmental conditions in which the mother lives in.

In this study, Mosley and Chen (1984) model is adopted because it is a useful framework through which to view the effects of different determinants on childhood mortality. This framework focuses on the proximate 
(direct) and indirect factors affecting child health and survival. The proximate determinants of mortality described as biological and behavioural causes of death include such factors as sex, maternal age, number of previous births, spacing between births, birth weight and breastfeeding. Indirect determinants of mortality concern certain environmental, socio-economic and cultural factors such as place of residence, ethnicity, mother's and husband's education, marital status of mother, mother's occupation, water and toilet facilities and health service availability factors that influence mortality through the direct variables.

\section{Data and methods}

Data sources and types

The analysis is based on the Demographic and Health Surveys which were conducted in 1998 and 2003 for South Africa and Kenya respectively (Kenya Central Bureau of Statistics, 2003; Department of Health, South Africa, 1998). Both surveys collected information on mortality among children under five years of age.

All the mortality rates presented in this paper are calculated from information drawn from the questions asked in the birth history section of the women's questionnaire. Preceding the birth history, probing questions are posed on the aggregate childbearing experience of respondents (i.e. the number of sons and daughters who live with the mother, the number who live elsewhere, and the number who have died). In the birth history, for each live birth, information is collected on sex, month and year of birth, survivorship status, and current age, or if the child had died, the age at death.

The analysis of Kenyan data is based on approximately 3270 most recent live births born 5- 10 years before the 2003 Kenya Demographic and Health Survey to all women aged 15-49 interviewed in the survey. To avoid the problem of multiple births the target child was the most recent birth born in the period 1993-1998. Whereas this cut-off point was taken so as to allow full exposure to risk of dying, unfortunately, in this process, little can be done to minimize the possibility of missing out on births to older women who had had children 5-10 years previously. Those children may have had worse survival prospects.

Of the 3270 most recent live births born 5-10 years before the 2003 $\mathrm{KDHS}$, approximately 97 died in the neonatal stage and 117 died in the postneonatal stage. In the case of child mortality the analysis was based on approximately 3056 children who had survived the neonatal and post-neonatal stages and of these 102 died between ages one to five.

On the other hand the analysis of the South African data is based on a total of 4/38 most recent live births born 5-10 years before the 1998 South African Demographic and Health Survey. Of these, 74 died at neonatal stage, 86 were post-neonatal deaths, 29 died between ages one to five and 3949 survived beyond age five.

The dependent variable used in this study is categorical with four independent occurrences namely neonatal, postneonatal, child mortality and survived to age 5. Thus Died has 4 categories (0-I month mortality, 2-12 months, 13-60 months, or survived to age 5). Covariates are grouped in all cases. For ordi- 
nal variables, Spearman correlations will be given whereas for categorical variables, Chi-square test results will be given.

The exposure to risk of dying is examined for the most recent births born $5-10$ years prior to the date of the interview. Various measures of exposure status are used. These include the following risk factors: toilet facilities (grouped into flush toilet, latrine and bush or no facility); water source (piped water, well, and river or stream or other source); maternal education; maternal literacy; partner's education; partner's occupation; place of residence of mother; place of previous residence of mother; place of childhood residence of mother; ethnicity or race; maternal age at birth of child; maternal age at first marriage; marital status and birth order

Some of the factors usually associated with survival were examined and they did not vary when the inclusion of the main risk factors was made. They were therefore not considered as possible confounding factors and therefore dropped out of the logistic analysis. The main risk factors considered in the logistic analysis of the $2003 \mathrm{KDHS}$ were as follows: mother's educational attainment; region; ethnicity and type of toilet facility. From the 1998 SADHS, the main risk factors included in the logistic analysis were as follows: mother's educational attainment, partner's educational level, childhood place of residence and type of toilet facility.

\section{Methods of analysis}

Two methods of analysis are used in this study. First the differences in mortality levels between population groups were investigated through bivariate analysis which forms the basis for the application of the logistic analysis. All the most recent births born 5-10 years prior to the survey were examined and proportions of children who died during the neonatal, post-neonatal, infant and late childhood stages by risk factor category were calculated using the Statistical Analysis Systems (SAS) software package. Analysis of the relationship between all risk factors and the proportion of children dead among the most recent births born 5-10 years prior to the survey by risk factor category was done.

Based on the initial findings of the bivariate analysis, a second analysis, logistic analysis, was performed with some variables re-categorized to facilitate analysis and interpretation of the results.

Logistic analysis is useful for situations in which you want to be able to predict the presence or absence of a characteristic or outcome based on values of predictor variables. It is suited to models where the dependent variable is categorical. The researcher can specify details of how the logistic analysis procedure will handle categorical variables. It was applied in this study to establish the socio-economic and demographic variables that are important risk factors for infant and child mortality. The method provides model chi-square and predicted probabilities estimated via the generalized models, among other statistics.

The approach adopted in this study was to look at variables that were logically related and keep the one(s) that remained significant with the other member of the pair in the model. This 
process is in the spirit of a stepwise procedure, but variables were selected for consideration by the logic of their relationship rather than simply relying on a series of statistical tests. The variables that looked to be important predictors of the mortality category in each data set were identified at the completion of this process. It was considered easier to see the effect of those variables that were selected by pairwise examination of variables, by looking at the probabilities estimated via the generalized models rather than give many odds ratios.

\section{Results and discussion}

The results of the analyses described in the preceding section are presented and discussed in this section. First, the results of the bivariate analysis based on the 1998 SADHS and the 2003 KDHS are presented in terms of number of deaths per 1000 live births occurring at the neonatal, post-neonatal and childhood ages 1-4. In the second part of this section, the results of the logistic analysis are examined.

\section{Bivariate analysis}

Childhood mortality by education and literacy Mother's education and literacy appear to be linked to mortality at the neonatal, post-neonatal, infant and childhood stages. In this analysis mother's level of education is taken as a variable indicative of her level of understanding of hygiene and health care and of the need not only to attend pre-natal and postnatal clinics but also to see that trained medical personnel attend her and her child during and after birth. As would be expected, the results shown in Table I suggest the existence of a linkage between mother's level of education and her children's survival chances. According to the analysis of the 2003 data from the Kenya Demographic and Health Survey (KDHS, 2003), children whose mothers had some secondary education had decreased levels of neonatal mortality (22 per 1000), as well as child mortality (28 per 1000) compared to 37 and 42 for no education; 32 and 33 for primary incomplete; and 18 and 13 for primary complete. However, it can be observed from the results depicted in Table I and Figures I to 3 that this relationship is a complex one because mortality, particularly postneonatal and infant mortality, does not decrease uniformly with increasing level of maternal education in Kenya. Rather an inverted U-shaped pattern of the education-mortality relationship is observed particularly for post-neonatal mortality based on the 2003 KDHS data.

This unexpected relationship, also observed in previous KDHS surveys (1993 and 1998), does not seem to exist when partner's educational level is considered although there are a few cases in the cells corresponding to secondary and above educational category. It is difficult to explain this phenomenon, but it is possible that mothers with some primary education tend to bottlefeed their children, with the likely risks associated with dirty bottle feeding practices. In an attempt to explain this unexpected pattern it has been pointed out that at least two parts of the country, Rift Valley and Coast provinces, exhibit mortality levels that are lower than would be expected based on their levels of maternal education (KDHS 1998, p.93). Further insight on the edu- 
cation-mortality relationship is provided in the results of the logistic analysis.

Table I: Neonatal, post-neonatal, and child mortality rates, for the most recent births born 5-10 years before the survey, by socio-economic and demographic characteristics, Kenya, 2003

\begin{tabular}{|c|c|c|c|c|}
\hline $\begin{array}{l}\text { Socioeconomic } \\
\text { characteristic }\end{array}$ & $\begin{array}{c}\text { Neonatal } \\
\text { mortality } \\
(\mathrm{NN})\end{array}$ & $\begin{array}{c}\text { Post- } \\
\text { neonatal } \\
\text { mortality } \\
\text { (PNN) }\end{array}$ & $\begin{array}{c}\text { Infant } \\
\text { mortality } \\
(\mathrm{lq0})\end{array}$ & $\begin{array}{c}\text { Child } \\
\text { mortality } \\
(4 q \mathrm{l})\end{array}$ \\
\hline \multicolumn{5}{|c|}{ Mother's education } \\
\hline No education & 37 & 38 & 75 & 42 \\
\hline Primary incomplete & 32 & 44 & 75 & 33 \\
\hline Primary complete & 18 & 21 & 39 & 13 \\
\hline Secondary+ & 22 & 0 & 66 & 28 \\
\hline \multicolumn{5}{|c|}{ Partner's education } \\
\hline No education & 46 & 39 & 85 & 39 \\
\hline Primary incomplete & 29 & 39 & 68 & 33 \\
\hline Primary complete & 18 & 11 & 29 & 14 \\
\hline Secondary+ & 0 & 47 & 47 & 0 \\
\hline \multicolumn{5}{|c|}{ Mother's literacy } \\
\hline Cannot read at all & 41 & 38 & 79 & 45 \\
\hline Can read & 25 & 35 & 59 & 25 \\
\hline \multicolumn{5}{|c|}{ Residence } \\
\hline Urban & 24 & 38 & 62 & 29 \\
\hline Rural & 32 & 35 & 67 & 32 \\
\hline \multicolumn{5}{|c|}{ Childhood place of residence } \\
\hline City/Town & 16 & 63 & 79 & 30 \\
\hline Countryside & 33 & 30 & 63 & 32 \\
\hline Abroad & 32 & 16 & 48 & 32 \\
\hline \multicolumn{5}{|c|}{ Place of previous residence } \\
\hline City/Town & 33 & 40 & 72 & 35 \\
\hline Countryside & 20 & 34 & 54 & 32 \\
\hline \multicolumn{5}{|c|}{ Province } \\
\hline Nairobi & 28 & 41 & 69 & 22 \\
\hline Central/Eastern & 23 & 15 & 38 & 18 \\
\hline Coast/Nyanza/Western & 25 & 53 & 78 & 46 \\
\hline Rift Valley & 37 & 24 & 61 & 22 \\
\hline North Eastern & 59 & 51 & 110 & 39 \\
\hline
\end{tabular}


African Population Studies Vol 24, I\&2 (2010)

Table I continued ....

\begin{tabular}{|c|c|c|c|c|}
\hline $\begin{array}{l}\text { Socioeconomic } \\
\text { characteristic }\end{array}$ & $\begin{array}{c}\text { Neonatal } \\
\text { mortality } \\
(\mathrm{NN})\end{array}$ & $\begin{array}{c}\text { Post- } \\
\text { neonatal } \\
\text { mortality } \\
(\mathrm{PNN})\end{array}$ & $\begin{array}{c}\text { Infant } \\
\text { mortality } \\
(\mathrm{Iq0})\end{array}$ & $\begin{array}{c}\text { Child } \\
\text { mortality } \\
\left(4 q^{\prime}\right)\end{array}$ \\
\hline \multicolumn{5}{|c|}{ Mother's age at birth of child } \\
\hline$<20$ & 33 & 53 & 86 & 28 \\
\hline $20-29$ & 24 & 27 & 51 & 26 \\
\hline $30+$ & 38 & 43 & 81 & 43 \\
\hline \multicolumn{5}{|c|}{ Marital status } \\
\hline Never married & 8 & 17 & 25 & 17 \\
\hline Currently married & 28 & 36 & 63 & 30 \\
\hline Formerly married & 48 & 43 & 90 & 41 \\
\hline \multicolumn{5}{|c|}{ Age at first marriage } \\
\hline$<20$ & 31 & 43 & 74 & 34 \\
\hline $20-29$ & 29 & 26 & 56 & 28 \\
\hline $30+$ & 39 & 0 & 38 & 39 \\
\hline \multicolumn{5}{|c|}{ Birth order } \\
\hline 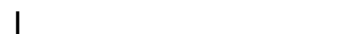 & 36 & 28 & 64 & 21 \\
\hline 2 & 19 & 30 & 49 & 27 \\
\hline 3 & 20 & 34 & 55 & 28 \\
\hline 4 & 36 & 28 & 64 & 22 \\
\hline 5 & 41 & 45 & 86 & 26 \\
\hline 6 & 25 & 50 & 75 & 33 \\
\hline $7+$ & 33 & 51 & 84 & 69 \\
\hline \multicolumn{5}{|c|}{ Source of drinking water } \\
\hline Piped water & 20 & 31 & 50 & 26 \\
\hline Well & 31 & 40 & 71 & 41 \\
\hline River & 34 & 36 & 71 & 34 \\
\hline Other & 35 & 33 & 68 & 19 \\
\hline \multicolumn{5}{|c|}{ Type of toilet facility } \\
\hline Flush & 29 & 26 & 55 & 15 \\
\hline Pit & 24 & 29 & 53 & 32 \\
\hline Other & 44 & 54 & 98 & 34 \\
\hline
\end{tabular}


Table I continued ...

\begin{tabular}{|c|c|c|c|c|}
\hline \multicolumn{5}{|c|}{ Ethnicity } \\
\hline Embu/Kamba/Kikuyu/Meru & 22 & 14 & 37 & 20 \\
\hline Kalenjin/Masai/Turkana & 40 & 21 & 61 & 15 \\
\hline Kisii/Luhya/Luo/Kuria & 27 & 63 & 89 & 51 \\
\hline Mijikenda/Taita/Taveta & 23 & 29 & 52 & 26 \\
\hline Somali & 56 & 6 & 113 & 41 \\
\hline Other & 20 & 20 & 41 & 20 \\
\hline \multicolumn{5}{|c|}{ Respondent's occupation } \\
\hline Not working & 37 & 43 & 80 & 26 \\
\hline Profess/Technical/Managerial & 6 & 19 & 25 & 13 \\
\hline Clerical/Sales/Service & 27 & 34 & 61 & 37 \\
\hline Agric. self-employed & 28 & 33 & 61 & 35 \\
\hline Household \& domestic & 20 & 40 & 59 & 40 \\
\hline Manual & 37 & 37 & 74 & 42 \\
\hline \multicolumn{5}{|c|}{ Partner's occupation } \\
\hline Profess/Technical/Managerial & 23 & 20 & 44 & 9 \\
\hline Clerical/Sales/Service & 32 & 39 & 72 & 18 \\
\hline Agricultural- self employed & 38 & 36 & 73 & 45 \\
\hline Household \& domestic & 33 & 33 & 67 & 33 \\
\hline Manual & 24 & 41 & 65 & 36 \\
\hline \multicolumn{5}{|c|}{ Religion } \\
\hline Roman Catholic & 24 & 33 & 57 & 23 \\
\hline Protestant/Other Christian & 28 & 32 & 60 & 33 \\
\hline Muslim & 44 & 58 & 102 & 42 \\
\hline No Religion & 34 & 23 & 57 & II \\
\hline Other & 0 & 0 & 0 & 0 \\
\hline
\end{tabular}

On the other hand, the bivariate results based on the 1998 South African Demographic and Health Survey (see Table 2 and Figures I to 3) generally exhibit the expected pattern whereby neonatal, post-neonatal, infant and child mortality tend to be higher among children born to mothers with no education than those with some primary education or higher. This phenomenon is also observed for neonatal, post-neo- natal and infant mortality when partner's education is used. However, the numbers in the cells corresponding to the secondary and above category are too small. Hence it is difficult to make any meaningful conclusion on the relationship. A further analysis of infant mortality based on the 1998 SADHS, using survival techniques, was undertaken and the results confirmed the existence of substantial variations in the 
proportions of infants surviving by clearly depicted in Figure 6. maternal education. These results are

Table 2: Neonatal, post-neonatal, and child mortality rates, for the most recent births born 5 - 10 years before the survey, by socio-economic and demographic characteristics, South Africa, 1998

\begin{tabular}{|c|c|c|c|c|}
\hline $\begin{array}{l}\text { Socioeconomic } \\
\text { characteristic }\end{array}$ & $\begin{array}{c}\text { Neonatal } \\
\text { mortality } \\
(\mathrm{NN})\end{array}$ & $\begin{array}{c}\text { Post- } \\
\text { neonatal } \\
\text { mortality } \\
\text { (PNN) }\end{array}$ & $\begin{array}{c}\text { Infant } \\
\text { mortality } \\
(\mathrm{Iq0})\end{array}$ & $\begin{array}{c}\text { Child } \\
\text { mortality } \\
(4 q \mathrm{l})\end{array}$ \\
\hline \multicolumn{5}{|c|}{ Mother's education } \\
\hline No education & 28 & 44 & 72 & 14 \\
\hline Primary incomplete & 14 & 23 & 37 & 7 \\
\hline Primary complete & 19 & 16 & 35 & 7 \\
\hline Secondary+ & 16 & 12 & 27 & 0 \\
\hline \multicolumn{5}{|c|}{ Partner's education } \\
\hline No education & 33 & 33 & 65 & I \\
\hline Primary incomplete & 17 & 19 & 36 & 6 \\
\hline Primary complete & 0 & 0 & 0 & 0 \\
\hline Secondary + & 24 & 24 & 49 & 0 \\
\hline \multicolumn{5}{|c|}{ Mother's literacy } \\
\hline Cannot read at all & 41 & 38 & 79 & 45 \\
\hline Can read & 25 & 35 & 59 & 25 \\
\hline \multicolumn{5}{|c|}{ Residence } \\
\hline Urban & 16 & 15 & 31 & 6 \\
\hline Rural & 20 & 26 & 46 & 8 \\
\hline \multicolumn{5}{|c|}{ Childhood place of residence } \\
\hline City/Town & 16 & 13 & 27 & 6 \\
\hline Countryside & 20 & 26 & 46 & 7 \\
\hline \multicolumn{5}{|c|}{ Place of previous residence } \\
\hline City/Town & 19 & 13 & 32 & 7 \\
\hline Countryside & 17 & 26 & 42 & 8 \\
\hline \multicolumn{5}{|c|}{ Province } \\
\hline Western Cape & 0 & 4 & 4 & 4 \\
\hline Eastern Cape & 17 & 29 & 47 & 7 \\
\hline Northern Cape & 18 & 21 & 38 & 3 \\
\hline Free State & 9 & 15 & 25 & 9 \\
\hline KwaZulu Natal & 30 & 21 & 51 & 11 \\
\hline North West & 23 & 9 & 31 & 6 \\
\hline Gauteng & 11 & 19 & 30 & 6 \\
\hline Mpumalanga & 25 & 27 & 52 & 7 \\
\hline Northern Province & 15 & 22 & 37 & 7 \\
\hline
\end{tabular}


Table 2 continued ...

\begin{tabular}{|c|c|c|c|c|}
\hline $\begin{array}{l}\text { Socioeconomic } \\
\text { characteristic }\end{array}$ & $\begin{array}{c}\text { Neonatal } \\
\text { mortality } \\
(\mathrm{NN})\end{array}$ & $\begin{array}{c}\text { Post- } \\
\text { neonatal } \\
\text { mortality } \\
(\mathrm{PNN})\end{array}$ & $\begin{array}{c}\text { Infant } \\
\text { mortality } \\
(\mathrm{lq0})\end{array}$ & $\begin{array}{c}\text { Child } \\
\text { mortality } \\
(4 q \mathrm{l})\end{array}$ \\
\hline \multicolumn{5}{|c|}{ Mother's age at birth of child } \\
\hline$<20$ & 24 & 18 & 42 & 9 \\
\hline $20-29$ & 15 & 20 & 34 & 5 \\
\hline $30+$ & 19 & 24 & 43 & 9 \\
\hline \multicolumn{5}{|c|}{ Marital status } \\
\hline Never married & 17 & 24 & 41 & 6 \\
\hline Currently married & 19 & 20 & 39 & 7 \\
\hline Formerly married & 14 & 19 & 32 & 7 \\
\hline \multicolumn{5}{|c|}{ Age at first marriage } \\
\hline$<20$ & 21 & 23 & 44 & 6 \\
\hline $20-29$ & 17 & 16 & 33 & 8 \\
\hline $30+$ & 10 & 20 & 30 & 15 \\
\hline \multicolumn{5}{|c|}{ Birth order } \\
\hline 1 & 21 & 21 & 41 & 8 \\
\hline 2 & 14 & 15 & 29 & 3 \\
\hline 3 & 8 & 14 & 22 & 8 \\
\hline 4 & 24 & 26 & 50 & 9 \\
\hline 5 & 19 & 22 & 40 & 9 \\
\hline 6 & 29 & 46 & 74 & II \\
\hline $7+$ & 30 & 39 & 69 & 0 \\
\hline \multicolumn{5}{|c|}{ Source of drinking water } \\
\hline Piped water & 16 & 18 & 34 & 6 \\
\hline Well & 22 & 28 & 50 & II \\
\hline River & 0 & 5 & 65 & 0 \\
\hline Other & 21 & 11 & 32 & 11 \\
\hline \multicolumn{5}{|c|}{ Type of toilet facility } \\
\hline Flush & 15 & 10 & 25 & 4 \\
\hline Pit & 19 & 23 & 42 & 8 \\
\hline Other & 20 & 36 & 57 & 10 \\
\hline \multicolumn{5}{|c|}{ Ethnicity } \\
\hline Black/African & 19 & 23 & 43 & 8 \\
\hline Coloured & 12 & 14 & 25 & 6 \\
\hline White & 6 & 0 & 6 & 6 \\
\hline Asian/Indian & 18 & 0 & 18 & 0 \\
\hline
\end{tabular}


Table 2 continued ...

\begin{tabular}{|c|c|c|c|c|}
\hline $\begin{array}{l}\text { Socioeconomic } \\
\text { characteristic }\end{array}$ & $\begin{array}{l}\text { Neonatal } \\
\text { mortality } \\
(\mathrm{NN})\end{array}$ & $\begin{array}{c}\text { Post- } \\
\text { neonatal } \\
\text { mortality } \\
(\mathrm{PNN})\end{array}$ & $\begin{array}{c}\text { Infant } \\
\text { mortality } \\
(\mathrm{Iq0})\end{array}$ & $\begin{array}{c}\text { Child } \\
\text { mortality } \\
\left(4 q^{\prime}\right)\end{array}$ \\
\hline \multicolumn{5}{|c|}{ Respondent's occupation } \\
\hline Not working & 17 & 24 & 41 & 7 \\
\hline Professl/Technical/Managerial & 10 & 10 & 20 & 0 \\
\hline Clerical/Sales/Service & 6 & 12 & 18 & 6 \\
\hline Agricultural- self employed & 0 & 0 & 0 & 0 \\
\hline Manual & 25 & 19 & 44 & 8 \\
\hline \multicolumn{5}{|c|}{ Partner's occupation } \\
\hline Profess/Technical/Managerial & 0 & 0 & 0 & 5 \\
\hline Clerical/Sales/Service & 18 & 4 & 22 & 6 \\
\hline Manual & 21 & 24 & 45 & 8 \\
\hline
\end{tabular}

At the same time, low levels of child mortality are linked to female literacy for the Kenyan data. The results shown in Table I point to the existence of remarkable differences in neonatal, post-neonatal, infant and child mortality between literate and illiterate mothers in Kenya. The definition adopted in the $2003 \mathrm{KDHS}$ for literacy is the ability to read and write in any language. It is clear from the results that the two variables are negatively associated. Here the negative correlation between female literacy and neonatal, post-neonatal, infant and child mortality levels implies that female literacy is associated with lower levels of mortality in Kenya. The possibility that the association of literacy with other explanatory variables is reducing the effect of this variable is investigated further through the logistic analysis.

\section{Mortality and place of residence}

Tables $I$ and 2 show the mortality differentials for children born to mothers in urban and in rural areas based on the $2003 \mathrm{KDHS}$ and 1998 SADHS respectively. The lower mortality of children of urban mothers is apparent in both data sets although the urban-rural differences appear to be greater for the 1998 SADHS than for the 2003 KDHS. Neonatal mortality is higher in rural areas (32 per 1000) than in urban areas (24 per 1000). A similar pattern is exhibited for post-neonatal and child mortality and that the rural-urban difference is especially pronounced during the neonatal mortality stage in Kenya. In the South African scenario depicted in the results shown in Table 2, the rates are generally lower than those for Kenya and that the urban-rural differences in post-neonatal and infant mortality seem to be more pronounced than those for Kenya depicted in Table I.

Urban areas are generally characterized by good health centres. There is adequate availability of transport means to hurry the sick or ill infants. Urban health centres do not only care for the infants but also for mothers during pregnancy, illness, deliveries, neonatal and postnatal care. Most of these if not all are not available in the rural areas' 
clinics and the mothers do not have the accessibility to such privileges. During pregnancies only a very few number would go for check-up and many deliveries are likely to take place at home. Deliveries associated with complications have a high risk that the infant would die before even taken out of the mother's womb. Yet in urban areas these are operated and most infants survive in urban areas because of the learned and skilled doctors who can help in case of complications at delivery. In the rural areas transport is very scarce and the clinics are too far from the rural homes.

Figure 1: Post-Neonatal Mortality Rates by Maternal Education

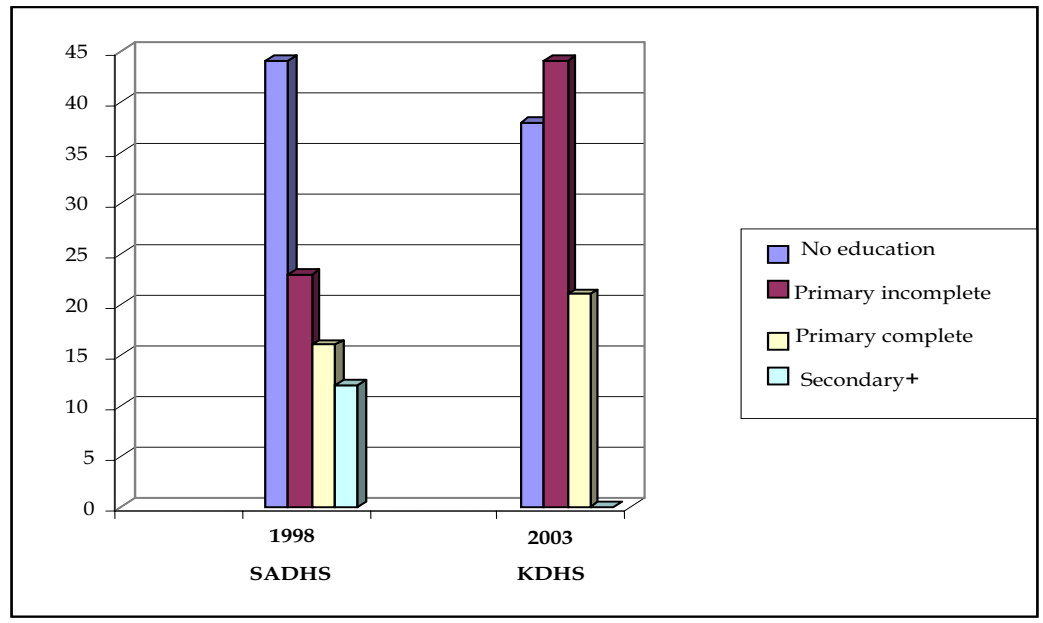

Figure 2: Infant Mortality Rates by Maternal Education

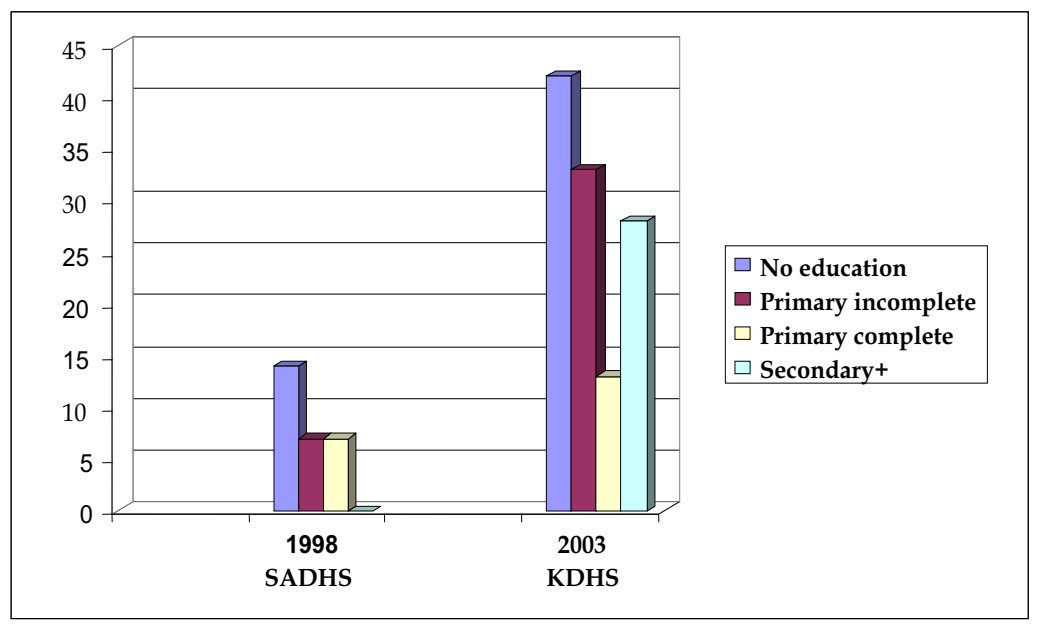


While emphasizing that infant and child mortality are especially sensitive to rural or urban residence it should be noted that in Africa, most educated people live in the urban areas and therefore the rural/urban differentials in mortality are likely to occur because urban residents are better educated, have more regular incomes, and benefit from more accessible health facilities than rural dwellers.

Figure 3: Child Mortality Rates by Maternal Education

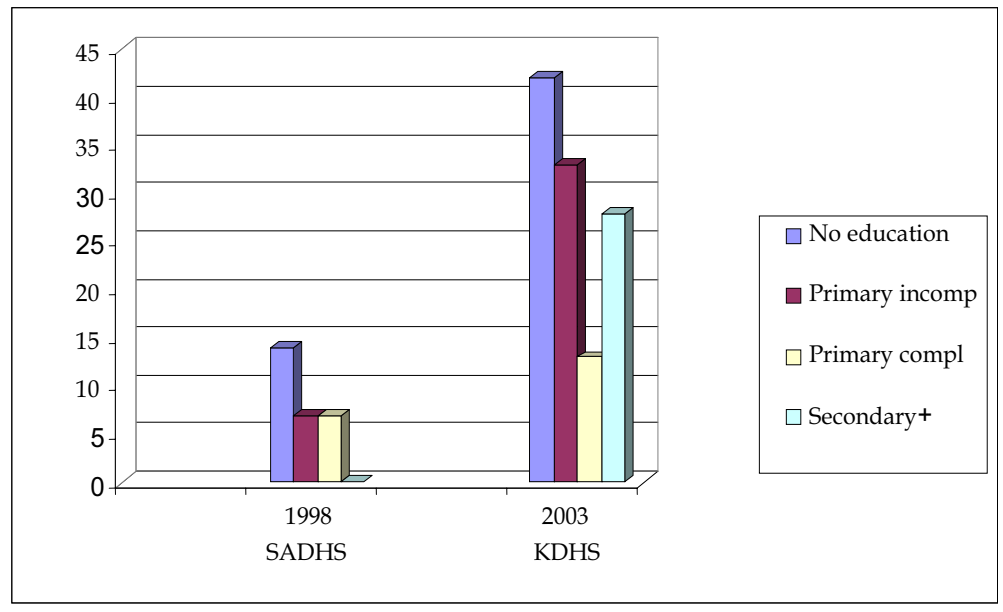

Figure 4: Infant Mortality by Type of Toilet Facility

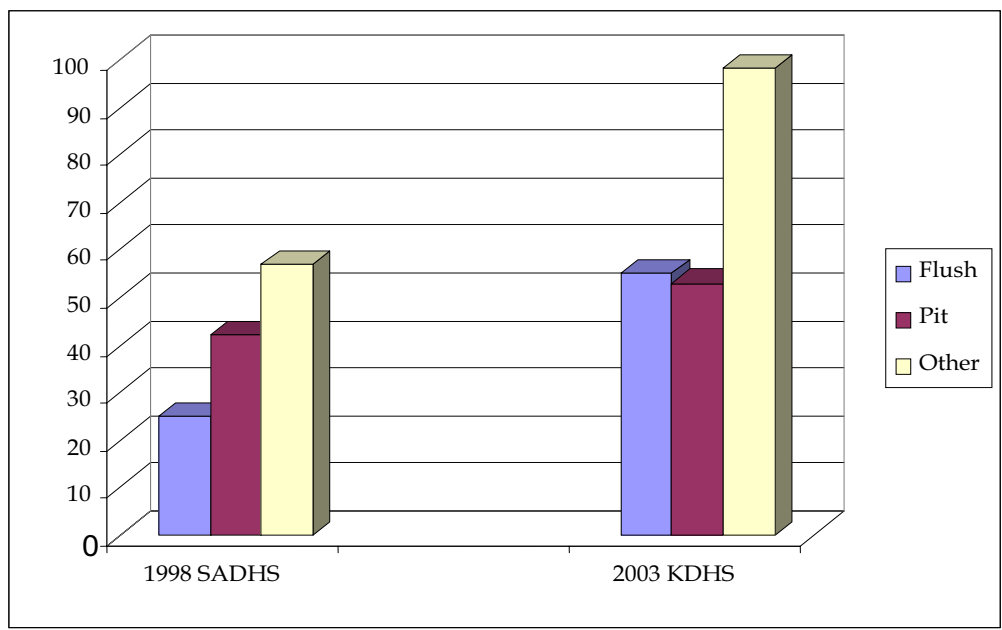

When childhood mortality is examined by place of childhood residence and also by place of previous residence the same picture seems to emerge with respect to the 1998 SADHS whereby children born to mothers whose childhood place of residence or place of previous residence was City/Town tend to 
experience much lower rates of mortality than the children of mothers who lived in the countryside. However, the Kenyan data exhibit a pattern that suggests higher urban mortality rates for post-neonatal and infant mortality. For instance according to the results based on the $2003 \mathrm{KDHS}$ shown in Table I, the mortality rates in city/town were 63 post-neonatal deaths per 1000 recent live births and 79 infant deaths per 1000 recent live births where the childhood place of residence was city/town compared to 30 and 63 per 1000 for the countryside respectively. The differences are generally more pronounced for neonatal, post-neonatal and infant mortality than for child mortality.

These urban-rural mortality differentials should, however, be taken as fully reflecting the differences in health conditions between urban and rural areas. Many of the urban mothers will have been recent migrants from rural areas, so that some of their children will have been born and died before they came to the towns.

Figure 5: Child Mortality by Type of Toilet Facility

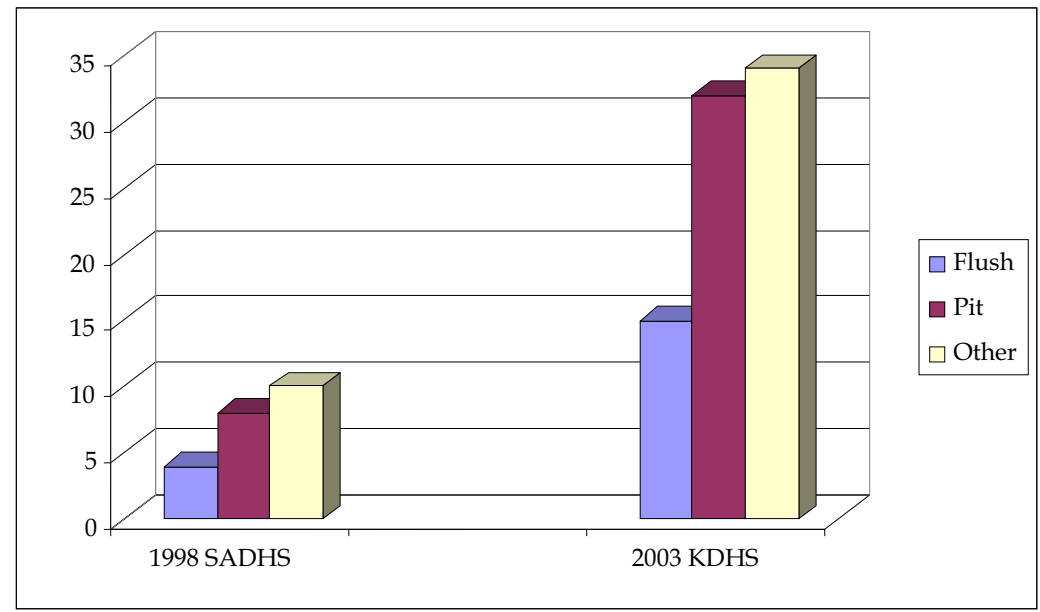

Mortality by ethnicity

The risk of children dying also varies widely across ethnic or racial groups. According to the results of the 2003 KDHS shown in Table I, the levels of neonatal, post-neonatal, infant and child mortality are highest among the Kisii/ Luhya/Luo/Kuria of Nyanza province and lowest among the Mijikenda/Taita/ Taveta of Coast province. Nyanza province is known for the prevalence of malaria which may account for the high mortality rates in this province. It must be noted however, that neonatal mortality appears to be outstandingly high among the Kalenjin/Masai/Turkana and Somali groups. This might be associated with lack of accessibility to clinics amongst other reasons. Results from the 1998 SADHS (see Table 2) clearly show that neonatal, post-neonatal, infant and child mortality for Blacks far 
exceeds that for the other races.

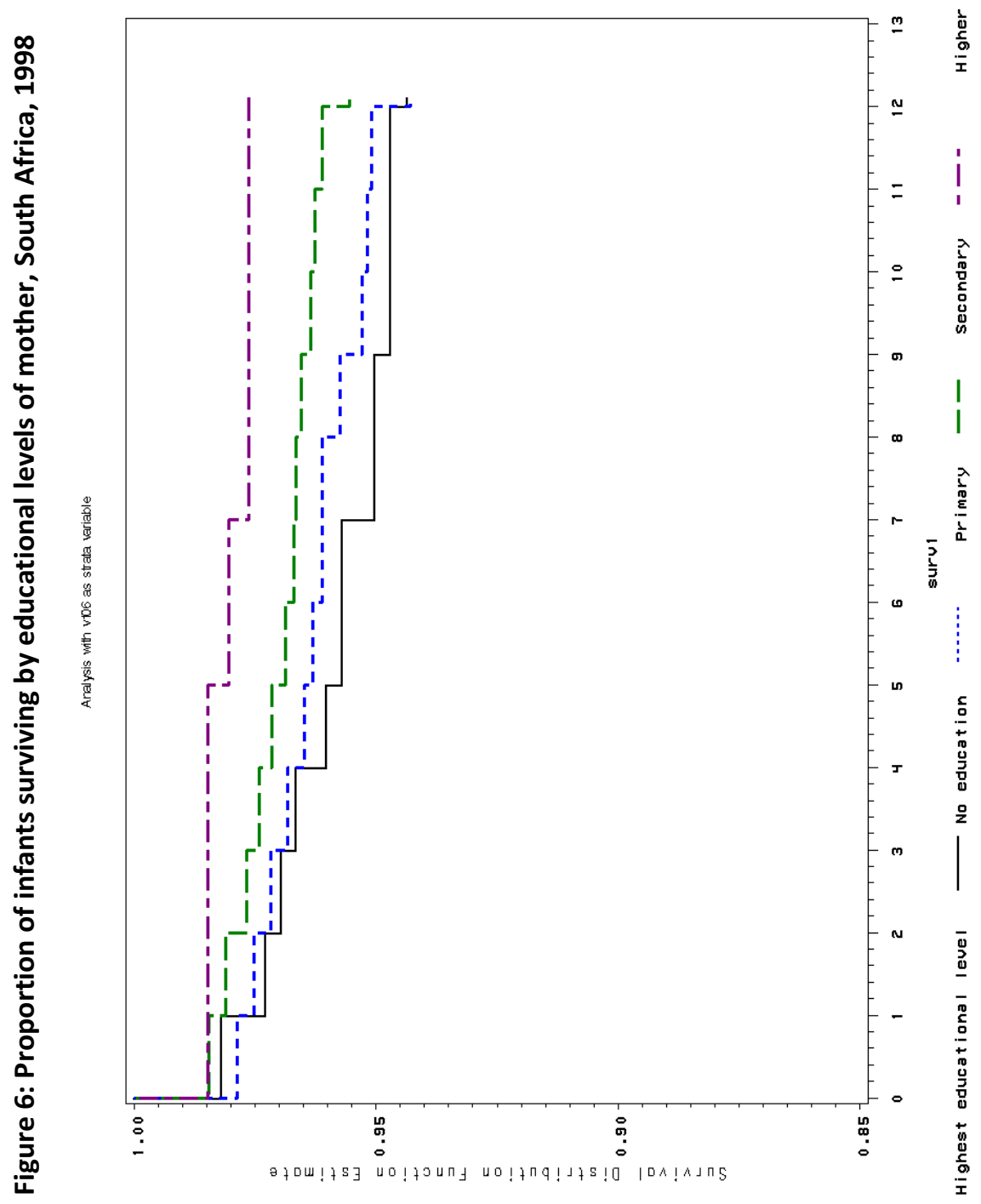

Ethnicity has sometimes been identified as an important variable associated with child mortality (Ubomba-Jaswa, 1988). However, this relationship may be explained by the fact that the type of region inhabited mainly by certain ethnic groups tends to be either healthy or unhealthy for reasons related to environmental health and socio-economic status and development. It is also possible that various tribal customs and practices might affect children's defences against environmental hazards. These may include traditions affecting breastfeeding, type and nutritional value of weaning foods, traditional treatments and remedies prescribed for childhood sicknesses, traditional practices relating 
to sanitation, and the disposal of human excrement, and modes of living in so far as they may affect overcrowding.

Mortality by birth order in the family

First-borns have a high risk of dying because of the age of mother or because of birth complications. This also may be due to the mother's inexperience in looking after the infant. The total number of children in the family also would limit the attention that would be given or granted to each child. Thus in times when the children are sick can even die before much attention from the parents.

It can be observed from a comparison of the results in Tables I and 2 that neonatal, post-neonatal and infant mortality differentials by birth order are especially markedly high for first order births and higher birth orders particularly for South Africa. This pattern is also evident for neonatal and infant mortality in the $2003 \mathrm{KDHS}$ but not for post-neonatal and child mortality. Most of the first birth orders are from women who bear children very early in their reproductive ages. This is likely to be accompanied by complications at child birth which may result in infant death. Even when the child is born it will be underweight, malnourished and perhaps anaemic. A combination of all these would increase the risk that the infant will die before the age of I year. Similarly high order births are associated with high neonatal, post-neonatal and child mortality as clearly demonstrated in the results based on the 1998 SADHS and $2003 \mathrm{KDHS}$.

Birth order and parity have been studied quite extensively and shown to exert strong influences on infant and child mortality. For example, studies by
Mosley and Chen (1984), Onyemunwa (1988) in Nigeria, Hobcraft et al. (1984) and many others have shown that mortality is much higher among children of teenage mothers and older mothers because young age reflects immaturity while old age is associated with birth complications. Mother's age may also be a measure of mother's experience with child care and whether the child is wanted or not. Other reasons include the deterioration of mother's health; mothers may be impaired from producing milk; competition for scarce resources; deterioration of mother's capacity to provide adequate care and restrictions in the distribution of scarce resources. Aaby et al. (1984) also observed that the number of children in a household is an important risk factor in that the older children are liable to introduce diseases such as measles into the household, and thereby infect young siblings who, for a variety of reasons, are more vulnerable.

In the South African scenario depicted in Table 2, the number of deaths in the cells for order 3 and upwards tends to decrease. One contributing factor is the recent decline in fertility which has contributed to low proportions of order 3 and upwards. The downward trend in fertility rates occurred as a result of the liberal access to contraception that was made available to the population in the circumstances in which the social, economic and cultural conditions for family planning was present.

\section{Mortality by age of mother at birth of the child and at first marriage}

Another differential in infant and child mortality is the age of mother at the time of birth of the child. Mother's age 
is used as a measure of mother's experience with child-care. Typically, infants and young children have a higher risk of dying if they are born to very young mothers or older mothers. In this analysis, mothers are classified as "too young" if they are less than 20 years old at the time of birth or first marriage, and "too old" if they are 30 years or more at the time of birth of the child or first marriage. Taucher (1983) cited in Dashtseren (2002) says that the risk of infant mortality increases when the mother is of an extreme age of childbearing period (i.e. less than 20 years and above 35 years). This is clearly evident from the results for Kenya and South Africa shown in Tables 1 and 2 which indicate that when age at birth is considered, neonatal, post-neonatal, infant and child mortality rates are generally higher for children born to young mothers under age 20 and older mothers above age 30 years compared to those of children born to mothers in their middle ages i.e. ages 20-29.

When mortality is examined by age at first marriage a similar effect is observed for neonatal mortality according to the KDHS data and for post-neonatal mortality in the case of South Africa. Kenyan children whose mothers marry at young ages (20 years or younger) or at older ages ( 30 years and above) are associated with higher rates of neonatal mortality than those born to mothers who marry at ages 20-29 years while their counterparts in South African experience higher rates of postneonatal mortality. Mortality is much higher among children of teenage mothers and older mothers because young age reflects physiological immaturity and stress that comes with it while old age may be associated with maternal depletion associated with repeated pregnancy and birth complications.

\section{Mortality by marital status}

A look at the rates of neonatal, postneonatal, infant and child mortality by marital status of their mothers as shown in Table I indicates that Kenyan children of mothers whose marriages have been broken by death of the husband, by divorce or separation had higher mortality at infancy and childhood than children born to never married or currently married women. There are very few never married women in the Kenyan sample and so a meaningful comparison could not be discerned easily. In the case of South Africa, the results shown in Table 2 display no major differentials by marital status although post-neonatal mortality is slightly higher for children born to never married women than for currently married and formerly married mothers.

In analysing the influence of marital status on child mortality it is considered that persons who are currently married represent stability such that they will have more privileges to facilitate better child care than those who were formerly married or still single. Thus their children would therefore be expected to experience lower levels of infant and child mortality than the children born to formerly married or single women. The variations in neonatal, post-neonatal and child mortality by marital status observed from the results in Tables I and 2 clearly support this expectation particularly for the 2003 KDHS where there is a clear indication that marriage creates a better environment suitable 
for the survival of children.

Mortality by occupation

Mortality has a considerable association with occupation. Among the first scholars to systematically investigate the relationship between occupation and mortality was Farr (1837), and many others, mainly doctors and actuaries have followed in his footsteps. Stevensen (1928) went further by relating mortality to class. The upper classes had both the lowest fertility and infant mortality rates whilst the lower classes had the highest levels on fertility and infant mortality he claimed.

Although mother's occupation can be considered a determining variable for child mortality it should be mentioned that other variables such as age, sex, socio-economic factors have direct or indirect effects. Mosley and Chen (1984) for example, showed that income influences mortality indirectly through proximate determinants such as food, water, clothing, bedding, housing, fuel/energy, transportation, hygienic/preventive care, and information. Certain diseases are dependent upon standards of living like diarrhoeal disease, which is greatly influenced by nutrition and personal health. Income is therefore necessary to provide babies with nutritious diet that prevents diarrhoea, a major cause of child deaths in sub-Saharan Africa.

The results presented in Table I clearly show that Kenyan children born to professional, technical or managerial workers have the lowest neonatal, post-neonatal, infant and child mortality (varying between 6 and 25 per thousand for Kenya) while children born to the non-working mothers and mothers engaged in manual work experience the highest mortality at the neonatal, postneonatal, infant and later childhood stages. The results based on the 1998 KDHS shown in Table 2 suggest that children born to Clerical/Sales/Service tend to experience lower neonatal and infant mortality than children of the other occupational groups. Similar associations were observed with regard to mortality and partner's occupation. However, the sample tended to dwindle with respect to non-working and professional partners.

\section{Childhood mortality by source of drinking water}

Another important factor of childhood mortality is water supply. The 1998 SADHS and 2003 KDHS asked questions about the source of water used by each household. This information is of interest both as a general index of socio-economic development, and because of the direct effect which the provision of a clean water supply is thought to have on infant and child mortality.

The results presented in Tables I and 2 indicate that according to the 2003 KDHS and 1998 SADHS, the proportion of children dead among women whose main source of water supply is piped is lower than that of women whose main source of water supply is river, well or other. There is therefore no doubt that unsanitary conditions can lead to the contamination of drinking water. This is especially so in households where drinking water is obtained from rivers that are contaminated. Due to various types of water-borne diseases that afflict children, source of water supply has a direct influence on child mortality. Incidence of diarrhoea for example depends mainly on availa- 
bility of uncontaminated drinking water and also on availability and use of hygienically constructed lavatories. Both quality and quantity of water supply are important determinants of exposure to diseases. Quality of water at the source and also in the household is essential for drinking and food preparation while adequate quantity permits bathing and cleaning.

Previous studies in Kenya have found that the low mortality districts of Central Province have a relative abundance of piped water while at the other extreme are the high mortality districts of Siaya, South Nyanza, Busia and West Pokot (Blacker et al., 1987). These studies have also shown that there are several Kenyan districts that are poorly provided with piped water and yet their childhood mortality levels are relatively low or moderate. Hence the relationship between child mortality and drinking water must look also at the quality of the water used for drinking.

\section{Childhood mortality by type of toilet facilities}

The other factor analyzed relates to type of toilet facilities. The means of sewage disposal has a direct influence on child survival. This is evident from the results shown in Tables $I$ and 2 and also in Figures 4 and 5, which indicate that children living in households that use flush toilets experience lower infant and child mortality than those born to households that use pit latrine or other such as bush for sewage disposal. According to these results, on average, use of pit latrine doubled infant and child mortality as compared to use of flush toilet. The corresponding differences based 1998 SADHS data are quite modest but a similar pattern was also observed. Obviously, unsanitary toilets or the absence of toilets lead to the breeding of flies and the transmission of diseases either through food taken by the child or the flies settling on the mouth or eyes of the child.

\section{Childhood mortality by region}

There is a considerable variation by provinces with the risks of children experiencing neonatal, post-neonatal, infant and child mortality varying widely across provinces. For example, the results based on the $1998 \mathrm{KDHS}$ shown in Table I suggest that neonatal mortality rate in North-Eastern province is almost twice as high as in Nairobi (59 deaths per 1000 recent live births compared with 28). It is interesting to note that Nairobi, being the most urbanized province in the country, does not necessarily exhibit the best mortality condition. Neonatal, post-neonatal, infant and child mortality rates are low in Central province and high in Coast, Nyanza, Western and North Eastern provinces. The provincial differentials seen here are consistent with those observed in other studies.

\section{Childhood mortality and religion}

Religiously, Kenya is quite diverse. Most Kenyans practise Christianity or Islam, with the majority stating that they are Christian. Nelson (1983) indicates that most pastoralist groups, found mainly in the northernmost districts, adhere primarily to indigenous religious beliefs. According to the results based on the 2003 Kenya Demographic and Health Survey children born to mothers who are Roman Catholics, Protestants or other Christian experienced lower mortality than the Muslims. There were very few cases in the cells corresponding to No Religion.

Akoto (1990) argues that mortality 
differentials between Christians and non-Christians in sub-Saharan African countries are due to certain factors associated with acceptance of Christianity rather than to any specific religious beliefs per se. Christianity in Africa is associated with social advancement, change, and rejection of traditional cultural elements in favour of Western cultural elements. A multiple classification analysis using World Fertility Survey data from Kenya and Cameroon showed that the higher rate of survival of Christian children is related to the advantages of Christians over other groups in female education, use of modern health care, partner's occupational status, and, in Kenya, the region of residence.

Logistic analysis

This section presents the results of the logistic analysis which were run using the SAS. The study looked at variables that were logically related and kept the one(s) that remained significant with the other member of the pair in the model. This process is in the spirit of a stepwise procedure, but variables were selected for consideration by the logic of their relationship rather than simply relying on a series of statistical tests. After completion of this process, there

$\begin{array}{lc}\text { Effect } & \text { DF } \\ \text { Birth order } & 6 \\ \text { Literacy } & 6 \\ \text { Ethnicity } & 15 \\ \text { Type of toilet facility } & 9\end{array}$

It should be noted that these are proportions or probabilities that are adjusted for values of covariates.

The generalized logit model based on the 1998 SADHS showed that the were four variables that looked to be important predictors of the mortality category in the Kenyan case and only two for South African data. It was considered easier to see the effect of these variables that were selected by pairwise examination of variables, by looking at the probabilities estimated via the generalized models rather than give many odds ratios.

First, the analysis based on the 2003 KDHS showed that the variables that seem to be important were as follows: educational attainment; birth order; literacy; ethnicity and type of toilet facility. The logistic analysis model for estimating probabilities based on generalized logits for multinomial outcomes allows us to get estimates of probabilities for

First, the analysis based on the 2003 KDHS showed that the variables that seem to be important were as follows: educational attainment; birth order; literacy; ethnicity and type of toilet facility. The logistic analysis model for estimating probabilities based on generalized logits for multinomial outcomes allows us to get estimates of probabilities for fixed levels of the covariates. The probabilities obtained were as follows:

$\begin{array}{cc}\text { Wald Chi-Square } & \operatorname{Pr}>\text { ChiSq } \\ 8.1730 & 0.2257 \\ 13.2617 & 0.0391 \\ 64.3604 & <.0001 \\ 20.7777 & 0.0137\end{array}$

main variables of importance were mother's educational attainment and type of toilet facility. The model pro- 
duced the following probabilities:

\author{
Effect \\ Mother's educational attainment \\ Type of toilet facility
}

To investigate the effect of each of these variables specifically (e.g. birth order), one would have to control for the other variable values and then vary the level of birth order and repeat the same process for the other covariates. The results obtained through this process tend to suggest that there is a strong effect of toilet facility than any other variable in Kenya whereas the mother's educational attainment is most significant in the South African results.

\section{Conclusion}

The low childhood mortality characteristic of South Africa is likely to have been achieved through the implementation of primary health care and also due to improved transportation and communication. Overall the results suggest that in order to reduce neonatal, post-neonatal, infant and child mortality, it is necessary to improve women's literacy and educational attainment with special focus to women without education. Similarly, the reproductive health program should pay special attention to the needs of lower educated women, for example the need to marry and engage in childbearing at a later age. It is also very important for governments to take action to provide clean water supply to households without piped water in order to reduce neonatal, post-neonatal and child mortality. It can be concluded that, according to the findings of this study, the high risk children in Kenya and South Africa are those born

$\begin{array}{ccc}\text { DF } & \text { Wald Chi-Square } & \operatorname{Pr}>\text { ChiSq } \\ 9 & 13.0781 & 0.1591 \\ 9 & 14.6744 & 0.1003\end{array}$

to mothers with low or without education, low occupations, who marry and bear children at early ages, partners with low occupation, poor water supply and living in the rural areas.

Several potential limitations of the study can be cited, including the lack of information about the characteristics of the mothers at the time of death of their children, the unavailability of data on some of the characteristics of partners. Nonetheless, the researcher affirms that the findings support the view that mother's education, literacy, type of toilet facility among others, are important factors of childhood mortality. It can be concluded that public health campaigns that urge parents to act responsibly by engaging in healthconscious behaviors are likely to help reduce childhood mortality.

\section{Acknowledgements}

This report has benefited from the generous assistance of Dr. Richard Madsen, a visiting statistical consultant from Missouri, USA who provided statistical and programming assistance. His assistance is greatly appreciated. However, the author accepts sole responsibility for any errors or misrepresentations of fact in this report.

\section{References}

Aaby, P. 1988. "Malnutrition and overcrowding - exposure in severe measles infection: A review of community studies." Review of 
Infectious Diseases, No. 10.

Akoto, E. 1990. "Christianity and infant and child mortality inequalities in black Africa." in Population. 1990 Nov-Dec; 45(6): 97I-9l.

Bicego G.T. and Boerma J.T. 1993. Maternal education and child survival: a comparative study of survey data from 17 countries. Social Science and Medicine.

Blacker J., Kibet M. and Werner L. 1987. "Analysis of Mortality Differentials in Kenya" In Proceedings of a seminar on Mortality and Society in sub-Saharan Africa held in Yaounde Cameroon, October 19-23, 1987.3.

Caldwell, J.C. 1979. "Education as a Factor in Mortality Decline: An Examination of Nigerian Data." In Population Studies, 1979, pp. 3954I3.

Dashtseren, A. 2002. Determinants of Infant and Child Mortality in Mongolia. Paper presented at the IUSSP Regional Conference, Bangkok, Thailand, 9-I 3 June 2002.

Department of Health. 2002. South Africa Demographic and Health Survey 1998. Full Report. Department of Health, Pretoria.

Department of Health. 2003. National HIV and Syphilis Antenatal SeroPrevalence Survey in South Africa: 2002. Department of Health, Pretoria.

Department of Health, Medical Research Council, OrcMacro. 2007. South Africa Demographic and Health Survey 2003. Pretoria: Department of Health.

Farr, W. 1974. "Vital Statistics or Statistics of Health, Sickness, Diseases and Death." In Wall, R. (1974) Mortality in Mid- $19^{\text {th }}$ Century Britain,
Gregg Reprints, Hampshire.

Hobcraft J.N. et al. 1985. "Socioeconomic Factors in Infant and Child Mortality: A Cross National Comparison" Population Studies, Volume 38, Number 2.

Kenya Demographic and Health Survey 1998. Macro International Inc. Calverton, Maryland, USA.

Marindo, R. and Hill, K. 1997. Trends and differentials in child mortality: Zimbabwe 1970-1994. Macro International, Demographic and Health Surveys. Calverton, Maryland.

Mencarini, L. 1999. An Analysis of Fertility and Infant Mortality in South Africa based on 1993 LSDS data. Paper presented at the Third African Population Conference held in Durban, South Africa, 6-10 December 1999.

Mosley, W.H. and Chen, L.S. (ed) 1984. "Child Survival." Population and Development Review 10 (Supplement), 1984, 25-40. Popu-lation Council, New York.

Nannan N., Bradshaw D., Timaeus I.M. and Dorrington R.E. 2000. The impact of HIV/AIDS on infant and child mortality in South Africa. XIIlth International AIDS Conference, Durban, South Africa, 8-13 July 2000. [Abstract of Poster MoPeD2507]

Nelson, H.D. 1983. Kenya, A Country Study. American University. Washington D.C.

Onyemunwa P. 1988. "Health care practices and use of health services as factors affecting child survival in Benin City Nigeria" in: African Population Conference, Dakar, Senegal 7-12 November, 1988. 
Romani, J.H. \& Anderson, B.A. 2002. Development, Health and the Environment: Factors Influencing Infant and Child Survival in South Africa. Cape Town. HSRC Publishers.

Rossouw J.P.H., Hofmeyer 1990. Infant and child mortality in South Africa: Levels, differentials and determinants. In: Mostert W.P. and Lotter J.M., eds., South Africa's Demographic Future. Human Sciences Research Council, 1990.

Rutaremwa, G. 2002. Differentials in infant and child mortality in East Africa (Uganda, Kenya, Tanzania). University of Pennsylvania Electronic Theses and Dissertations. Ubomba-Jaswa, P. 1988. An exploration of the relationship between ethnicity and early childhood mortality: the case of Kenya. Paper submitted to the African Population Conference, Da- kar, Senegal, November 7-12, 1988.

Udjo, E.O. 2004. Additional Evidence regarding Fertility and Mortality in South Africa and Implications for Population Projections. Directorate of Analysis, Statistics SA. Pretoria.

United Nations 1999. World Population Prospects. The 1998 Revision. Department of Economic and Social Affairs, Population Division. United Nations. New York.

United Nations 2000. World Population Prospects. Department of Economic and Social Affairs, Population Division. United Nations. New York.

United Nations Population Fund 2004. State of the World Population Report. New York: United Nations Population Fund.

United Nations 2005. Human Development Report 2005. New York: UNDP. 